\title{
Virtue Epistemology and the Sources of Epistemic Value
}

Lockie RHVE final version as sent Nov 2nd 2017.doc

\begin{abstract}
A basic question for virtue epistemology is whether it represents a 'third force' - a different source of normativity to that offered by internalism and externalism. It is argued that virtue epistemology does not offer us a distinct source of normativity. It is also argued that virtue theories offer us nothing that can unify the internalist and externalist sub-components of their preferred state of 'virtue'. Claims that phronesis can unify a virtuesbased axiology are specifically opposed.
\end{abstract}

\section{The ethics of belief: which ethics?}

The claim that normative epistemology should be regarded as the ethics of belief, may be seen as less contentious than often it is taken to be, provided we treat 'ethics' as a marker term holding place for the diversity in approaches to be found in normative ethics. Commonly, this phrase is taken to mark out a specifically deontic stance in epistemology - an adherence to deontic internalism ${ }^{1}$. However, if one's ethics is consequentialist we get a commitment to epistemic externalism; and if a virtue ethics we get a commitment to virtue epistemology. But what is this virtue ethics of belief? That is, what kind of value does it constitute?

One problem in assessing the prospects for virtue theory in epistemology is that this position has tended to be all things to all people. Is the kind of value represented by virtue theory a species of [deontic] internalism; or a species of [consequentialist] externalism; or a 'mixed' position (combining elements of both of these); or a 'third force' - something sui generis and original to virtue theory alone? All of these positions are represented in the literature, sometimes (not uncommonly, and apparently without embarrassment) with several of these stances on virtue-epistemic value appearing to be employed in one and the same philosophical position - as, for example, where a proponent of a strongly deontic but nevertheless 'mixed' virtue-responsibilism embraces the view that a virtuetheory of this type offers us an original, uniquely virtue-based ('aretaic') source of epistemic value.

I am of the opinion that, whatever other virtues virtue epistemology may possess, it does not offer us any new source of epistemic value; and that what follows from this should be a deflation of some of the more expansive claims made on behalf of virtue theory. I am of the opinion also that some of the vagueness and inclusive (cure-all) enthusiasm voiced by several generations of virtue theorists may be tempered by asking focused questions as to what kind of epistemic value is being offered, in any given case, by whichever virtue theory is in question. 


\section{Virtue reliabilism \& responsibilism}

Some virtue theorists are 'virtue responsibilists' and some are 'virtue reliabilists'. The former - e.g. Zagzebski, Montmarquet, Code - emphasize a deontic internalist conception of epistemic value (as a source of epistemic value) and the latter - e.g. Sosa, Greco, Goldman - an externalist conception of epistemic value (as a source of epistemic value). This is especially easy to see in the case of virtue reliabilism, where an interpretation of this position as something like a 'faculty reliabilism' is usually explicit, and where our understanding of virtue reliabilism may be assimilated to our understanding of other prefixed reliabilisms of the past (say, 'J-Rules' or 'E-Rules' consequentialisms). These latter, notably Goldman (1986) following a well-worn model from ethical theory, offer us a first-order rules-based position whose higher-order justification is that following such rules as if these were inviolate, will thereby lead to a greater maximization of the epistemic good - which consequentialist value remains the sole, genuine, axiological source. Though there is a divergence at the first-order level between, say, an act utilitarianism and a rules-utilitarianism, there is no divergence at the level of value-source. We have a merely 'virtual' deontology: at the level of axiological source, there is no sui generis deontological value.

Likewise with faculty reliabilism, we have, as it were, merely 'virtual' virtues: the source notion of epistemic value is maximization of actual (not expected) truth and/or minimization of falsity. There is no other axiological source than maximization of truth. Virtue reliabilism is an interesting first-order variant of generic epistemic consequentialism - distinct as the causal theory is from the counterfactual; or the J-rules theory is from process reliabilism. These are distinct theories all right, but they belong within the same axiological family; they compete at the first order level to offer us an account of the same species or kind of epistemic value: actual, objective, truth attainment (or error avoidance). As species' of epistemic consequentialism they compete to offer an account of the Epistemic Good, and reduce or otherwise subordinate their account of the Epistemic Right to this.

With virtue responsibilist approaches we have the reverse: accounts that emphasize the agent's diligent or remiss conduct with regard to the pursuit of truth. Was the agent a conscientious cognizer? Did the agent discharge her intellectual obligations dutifully ${ }^{2}$ ? On the assumption that epistemic value is to be understood thus, in terms of intellectual obligations (responsibilities, oughts) and on the further assumption that 'ought' implies 'can' one might think we should get the subjective, perspectival, access restrictions characteristic of epistemic deontology: we assess the agent for whether she has done all she can, relative to what she has access to - an epistemic access internalism. However, the addition of virtue-reliabilist objective requirements (of truth conducivity) will make problematic any such access constraints. Still, responsibilist approaches as such offer us a deontological species of epistemic normativity. Such theories, though they may differ at the first order level, belong within the same axiological family; they compete at the first order level to offer us an account of the same species or kind of epistemic value: assessing the fallible agent's expected, subjective, efforts after truth attainment; their 
diligence, their conscientiousness. As species' of epistemic deontology they compete to offer an account of the Epistemic Right, and do not reduce or otherwise subordinate their account of the Right to the Good.

Thus far, there is nothing in these two theory families to justify any view of virtue epistemology (responsibilist or reliabilist) as offering us a distinct or novel species of epistemic value - a 'third way' distinct from internalism [deontology] or externalism [consequentialism]. These are just first-order different accounts within, respectively, externalist and [deontic] internalist epistemology. Perhaps some virtue theorists are happy with this (explicitly, some virtue reliabilists are - though this enthusiasm is less marked among virtue reponsibilists). If they are, a question naturally arises as to why virtue theory is seen as a particularly distinct, interesting, radical or new approach to issues of epistemic value. (A somewhat different way of phrasing this would be to ask why, for example, virtue responsibilist and virtue reliabilist theories should nevertheless each be seen as virtue theories - as having this [what?] in common).

One answer often volunteered here comes from noting that many (most) virtue based accounts are nowadays 'mixed' accounts: requiring that substantial internalist and externalist conditions both be satisfied for the epistemic concept/goal-state in question to have been achieved (this latter being commonly knowledge, sometimes rationality, sometimes 'virtue' ${ }^{3}$ itself). An obvious problem with this answer is that a mixed account remains an account that derives its epistemic axiology from two more basic and underivative sources of epistemic value - still not a 'third way', still no $U r$ species of virtue normativity, of underivative virtue epistemic value. The source notion of value remains internalist or externalist or, as here, a combination of both.

Another problem is that very many (in fact, the great majority of) internalisms and (more contentiously) many externalisms are themselves 'mixed' accounts - so we have nothing to mark out a uniquely virtue-based third way. 'Mixed virtue responsibilism' remains distinct only at the level of either branding or first order detail from any generic deontic account in epistemology that falls short of a very extreme internalism - the latter of which Goldman (2009) calls 'existential' internalism and Weinberg (2006) calls 'strict' or 'absolute' internalism, of which the sole example which comes to mind is a Foley-style account of egocentric rationality - with this having in any event a Stoic (as opposed to Aristotelian) virtue equivalent (Annas 2003, Russell 1996). Even a Chisholmian deontic account (of knowledge) fully acknowledges, indeed emphasizes, the stringency of the externalist, objective truth requirement on knowledge, and that this requirement is an externalist requirement. Almost any internalist account of knowledge will have a truth requirement on knowledge, and that is a strong externalist requirement. Many will go beyond this in attempting to respond, with varying degrees of success, to stock externalist objections to their position.

The claim that most non-virtue-based epistemologies are 'mixed' becomes more contentious when applied to many externalisms, but short of a Sartwell $(1991,1992)$ Theaetetan account of knowledge as merely true belief (Theaetetus: true judgment) all externalisms embrace third (often fourth, and fifth) constraints on knowledge 
[/rationality] that are rarely exclusively motivated [and even more rarely well-motivated] within externalism alone. Clairvoyant-style examples are commonly used to embarrass externalist accounts. Rarely do the defenders of such accounts entirely bite the bullet and accept the verdict of their opponents in such cases - that such thought experiments' agents must be held to have knowledge in the presence of reckless and wholesale epistemic irresponsibility: to acquiesce in this conclusion without a fight. At the level of axiological source (not epistemological detail) 'mixed virtue reliabilism' remains only terminologically distinct from any of many (acknowledged: perhaps not all) generic externalist accounts.

\section{Pluralism is distinct from mixed virtues theory}

Here, as a qualificatory aside, the reader is cautioned to take care to distinguish the issue of mixed virtues theory from pluralism. These are quite distinct issues. A pluralist account is (I take it) a 'thick' account that recognizes many separate epistemic or ethical virtues (often but not always with an incommensurability 'no common currency' thesis alongside; and often, but not always with a concomitant "no overarching - e.g. consequentialist or deontic - superordinate, 'thin', 'master virtue' thesis" attached). So, the claim that there are separate virtues of wisdom, justice, compassion, temperance etc., but no unifying master virtue of e.g. justice or phronesis or eudemenia or the Good-would be one such pluralist position. But as I noted in my 2008, in both the classical (e.g. Aristotelian) and in the modern texts, there is chronic, willful, equivocation around this issue, with virtue theorists being all things to all people - saying highly inconsistent things in neighboring paragraphs. In any event, mixed theories per se don't directly concern themselves with these issues, being far more concerned with the nature of our 'thin' axiological source than matters pertaining to thick pluralist virtues. The mixed theorist per se is one who insists upon a deontic and a consequentialist source of epistemic or ethical value needing to be present for our epistemic or ethical goal state to be achieved. Any additional commitment to 'pluralism' is just that - additional, separable. So, to pick a generic mixed virtue epistemic account of knowledge: a mixed virtue theorist would require the knower to actually attain truth, of her beliefs (and to do so, say, reliably); yet also to do so through responsible intellectual conduct. Both these components (the deontic, responsibilist component and the consequentialist, reliabilist component) pertain to 'thin', overarching, generalist axiological source. Discussing issues of pluralism further is then simply beyond the scope of this paper - whatever issues pertain to the relation between pluralism and mixed virtue theory are a separate topic of research.

\section{Virtue Epistemology does not provide a sui generis source of epistemic value}

Virtue theories may perhaps be seen as a new set of theories in epistemology (I shall not argue the contrary, in any event) but despite frequent claims to the contrary they do not offer us a new species of epistemic value, a new epistemic axiological kind - a distinct and underivative source of specifically aretaic value. They are a construct, a conjunction, a portmanteau, out of our existing, and wholly orthogonal, epistemic value-kinds. Virtue theory does not represent a genuine third force as regards epistemic value. The state or 
kind of 'virtue', taken by these theories as constituting epistemic success is not sui generis but derived. And despite many claims to the contrary, the [re-]emergence of virtue theory does not then represent a sea change in normative epistemology.

Familiar to all epistemologists, are the two dimensions of assessment offered by epistemic consequentialism and epistemic deontologism. The former of these assesses cognizers for objective truth conduciveness, however this be spelled-out - say, for exegetical purposes, in terms of a generic process reliabilism. For any given epistemic modality (visual perception, memory, etc.) and for any given further qualifications or restrictions as to class of cognitive operations, context, etc., and waiving generality issues, the cognizer may have very reliable or very unreliable cognitive processes - with success and failure seen as falling on a continuum: most truth conducive to least truth conducive. It is objective truth conducivity which concerns us here, this is an 'actual' consequentialism, it is an account of the Epistemic Good, an account of when a cognizer may be said to have satisfied the theoretical (non-regulative) desideratum of epistemic adequacy: Alston's 'objective', Chisholm's 'absolute' criterion of epistemic achievement (Lockie 2014a). This is one, crucial, axis of assessment we must deploy in epistemology: how much truth did the cognizer actually attain? How much error was actually avoided? Across similar scenarios how much truth will a cognizer set up like this be liable to attain? How much error will a cognizer set up like this be liable to avoid?

The second of our two axes of assessment - that offered by epistemic deontologism assesses epistemic agents for intellectual responsibility: for the diligence with which they pursued truth (or sought to avoid falsity) regardless of their actual, objective attainment thereof. On the assumption that 'ought' implies 'can' we get the access restrictions characteristic of internalism (the restrictions to subjective truth conducivity, or error avoidance): the restriction to an expected, not an actual consequentialism (i.e. not a consequentialism at all). How diligently did the epistemic agent act, from the perspective he occupies, how well did he marshal the resources he commands? We have an account of the Epistemic Right and not the Good; an account of when an agent may be said to have satisfied the regulative (practical) desideratum of epistemic adequacy, Alston's 'subjective', Chisholm's 'practical' criterion of epistemic achievement (after Richard Price's: 'practical virtue') (Lockie 2014a).

If, after nearly four hundred years of 'modern' post Cartesian epistemology, there is one matter that should by now be beyond dispute, it is that these two axes of assessment are orthogonal. There is a double dissociation between these two dimensions of assessment: objective versus expected truth maximization. As an aside, this is something that Stoic, as opposed to Aristotelian virtue theory partly appreciated (albeit in an inchoate and preenlightenment form); approaching this insight via the Stoics' distinction between skopos and telos (cf. Annas 2003, Wright 2013). This distinction applies to all stochastic (nondeterministic) arts - e.g. archery, medicine, rhetoric. Although both ancient terms are notionally 'teleological' (in our modern parlance) for the Stoics, the skopos is the target to be hit (usually a noun) the telos is the archer's aim at the target (usually a verb). Even if the skopos fails to be achieved (the target is missed, the patient dies, the jury is unconvinced) should the archer, doctor, lawyer, have practiced his craft skillfully he has 
done all he can and has achieved his telos. (The reverse direction of dissociation may be present also of course, as when unconscientious, unskilled or remiss aim strikes lucky). We may see the Stoic virtue theorists as being more nearly in the right direction than the Aristotelians in marking what, after the Cartesian revolution in early modern philosophy, became a vital double dissociation. We may stand in a reliable, etc, relation to the truth yet be intellectually irresponsible; or we may discharge our epistemic responsibilities ever so diligently yet fail to attain the truth.

if I abstain from giving my judgment on any thing when I do not perceive $i t$ with sufficient clearness and distinctness, it is plain that $I$ act rightly. . . But if I determine to deny or affirm, $I$ no longer make use as I should of my free will, and if $I$ affirm what is not true, it is evident that I deceive myself; even though I judge according to truth, this comes about only by chance, and I do not escape the blame of misusing my freedom; for the light of nature teaches us that the knowledge of the understanding should always precede the determination of the will. And it is in the misuse of the free will that the privation which constitutes the characteristic nature of error is met with (Descartes 1931: 176, emphases added). ${ }^{4}$

Attempts to 'problematize' or undermine this double dissociation - to argue or assume that somehow an agent's epistemic reliability and epistemic responsibility may be elided - are just wholly, utterly, uninteresting: indeed fatuous. Figuratively, these two dimensions of epistemic assessment (of epistemic achievement - or failure) may be placed at right angles; thus mapping out an appropriately Cartesian coordinate space, an 'epistemic circumplex'. 


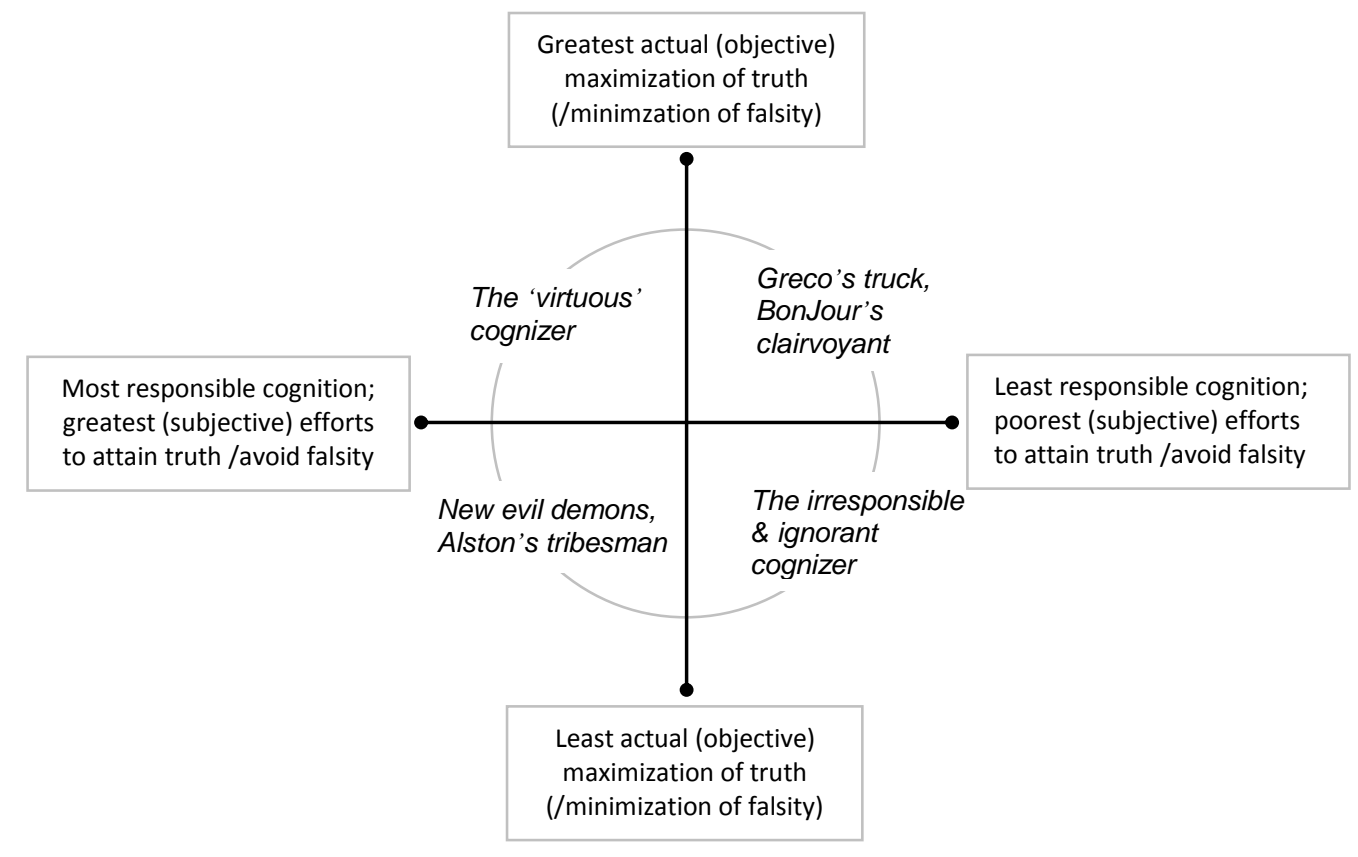

Figure 1. The Epistemic Circumplex. Source Lockie (2018). Author's copyright (C) Robert Lockie, reproduced by permission.

Famous and not-so-famous thought experiments can be inserted at will into the top right and bottom left quadrants above; I have mentioned one esoteric and one quotidian case for each, but there are of course a very large number of such cases, any of which would serve for use as examples. Should I be BonJour's clairvoyant then I will face Descartes' charge: "blame of misusing my freedom." And for every recherché thought experiment there is a quotidian case (that is: the dissociation is not merely conceptual) - as for [an adaptation of] the case of Greco's truck, whereby I irresponsibly and impulsively step off the cukerb to be suddenly alerted by a klaxon, as to a truck bearing down upon me, leading me to leap out of the way despite no discharge of any epistemic responsibility contributing to my state of knowledge - indeed, an active irresponsibility (Greco 2002: 296, adapted). Similarly, one may discharge one's obligations diligently yet be wholly unable to achieve the truth or avoid falsity - whether through being a victim of a New [actually not so new] Evil Demon, or simply by being an agent embedded within a sociocognitive milieu that does not permit one to attain the truth (Alston's 1985 example of the 'tribesman,' brought up to accept the traditions of his tribe as authoritative, and diligently working within these resources, with the epistemic resources of other intellectual perspectives wholly beyond his compass - cf. Lockie 2016a, 2016ㅁb).

This is hardly news to anybody. Since the double dissociation noted is intellectually unassailable, and wholly familiar to any epistemologist, what then are we to make of the idea that 'virtue' is, as a species of epistemic value, 'of its own kind' - sui generis, fundamental? I'd suggest we must simply abandon any such view as indefensible. One 
way to make this point is in terms of measurement. In our descriptive epistemology, the notion of epistemic success that is recognized by virtue epistemologists ('epistemic virtue', 'the virtuous cognizer') may be represented in terms of the two dimensions indicated (the possession of both deontic value and consequentialist value) - for this, see the upper left quadrant of the circumplex above. The converse is precisely not the case that is, possession of deontic value or consequentialist value cannot be fractioned or partitioned out of a supposedly sui generis, categorical, irreducible state ('being virtuous'). And, importantly, the specific nature of any given failure of epistemic achievement cannot be accurately and appropriately described without moving away from any such categorical, sui generis axiology to appraise the agent's epistemic achievements (and failures of achievement) on those separate registers (deontic and consequentialist) - registers which are recognized by a more traditional internalistexternalist conception of normative epistemology. Virtue epistemology offers us a cruder, categorical (nominal, 'type'-based) descriptive epistemology than the two dimensional measurement offered by traditional internalist/externalist epistemology. Virtue theorists routinely deploy these two dimensions in epistemic assessment anyway - as do all epistemologists. They represent the difference in emphasis between virtue responsibilists and virtue reliabilists after all - the former emphasize a 'West by Northwest' directional tendency within the top left quadrant of the coordinate space articulated above, the latter more a 'North by Northwest' tendency within this same quadrant. This is not something one can do unless these dimensional tendencies are fundamental, prior.

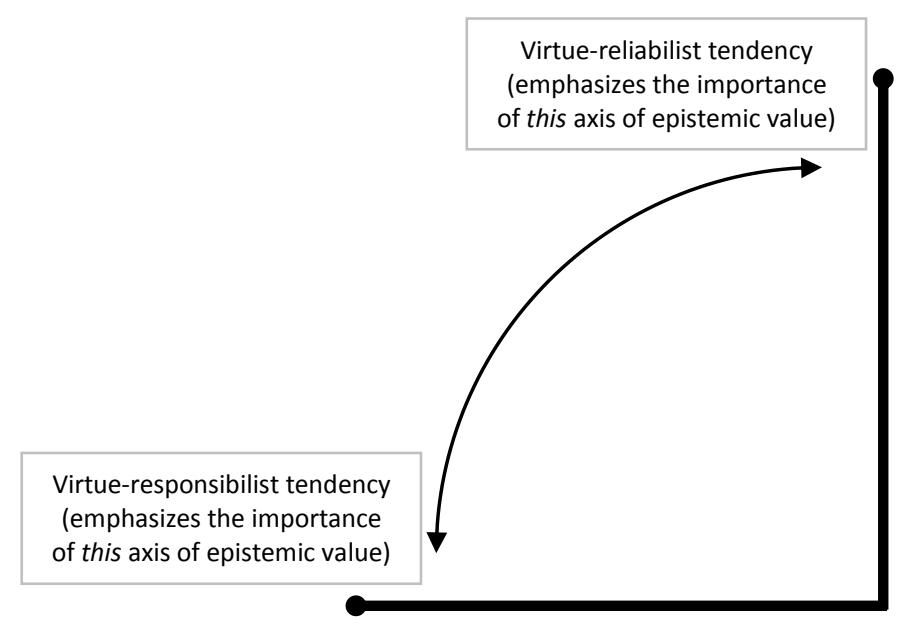

Figure 2. Domestic disputes between virtue responsibilists and virtue reliabilists (expanded top left sector of the circumplex above).

Note that the objection that, as a matter of fact, in most (non-skeptical, nearby-actual) worlds, the dimensions of epistemic assessment are not wholly orthogonal is not to the point. We are making conceptual points here - this is epistemology, after all. Conceptually, these twin dimensions of epistemic assessment are orthogonal. Note also, that many examples of beliefs that are justified but false, or true but without deontic 
justification, are entirely quotidian, and empirically, these axes of assessment may be really very orthogonal (Lockie 2016a).

\section{What might unify an aretaic axiology?}

The challenge from the above is that virtue theory appears to rest on two avowedly prior sources of epistemic value, consequentialist and deontic, lacking any sui generis value of its own - that is, being a conjunctive notion entirely derivative from these more fundamental axiological kinds. This is surely problematic given that familiar examples from four hundred years of mainstream epistemology establish that such 'responsibilist' and 'reliabilist' sources of value are doubly dissociated (Descartes 1931: 176; Locke 1975: IV, xvii, 24; Clifford 1999; Chisholm 1956a: 448, 1956b: 731; BonJour 1985: 45; Foley 2004). What then might unify these notions of epistemological value into a singular, distinctively and indispensably aretaic axiology? One sees a variety of candidate 'unifiers' in the work of virtue theorists. I acknowledge that I do not find them very convincing.

Here, as an epistemologist not sympathetic to virtue theory ${ }_{2}$ I must be on guard against accusations of straw-manning. Jointly necessary and sufficient criteria are not typically (at least, explicitly) advanced by virtue theorists in answer to this 'unification' question, and thus targeting particular candidate suggestions offered by a heterogeneity of virtue theorists requires me to offer the caveat: if the cap doesn't fit, don't wear it. Still, virtue epistemologists do adopt a variety of stances in the vicinity of this problem. In particular, one encounters claims that some or several out of the following may serve to unify the 'responsibilist' and 'reliabilist' sources of value into a singular, unitary, distinctively aretaic source of epistemic value 5 .

- Normativity claims - virtue epistemology represents a distinctively values-based approach to epistemology.

- Responsibility claims - virtue epistemology represents a distinctively responsibilist, 'oughts-based' approach to epistemology.

- Agential evaluation claims - virtue epistemology, in contrast to other approaches to epistemology, evaluates the agent rather than, say, solely the process or proposition or belief under appraisal.

- Phronesis as a unifier claims - practical wisdom (phronesis) unifies responsibility and reliability into one 'virtue-based' axiology.

- The virtues themselves unify responsibility and reliability. The virtues are prior and embody both responsibilist and reliabilist components.

- What defines virtue epistemology is a claim about the direction of analysis: justification/knowledge and belief evaluation should be defined in terms of virtues and agent evaluation rather than virtues and agent evaluation being defined in terms of justification/knowledge and belief evaluation.

The first two of these points are sometimes elided. One sees this in talk of 'credit' for believing correctly (and the attempt by some virtue theorists to appropriate this general 
deontic/normative point in epistemology to the specifics of virtue theory). We see the first two of these claims illustrated in the first two sentences of the following (merely illustrative) passage. The third of these claims is illustrated in the last two sentences.

On the one hand, virtue epistemologists agree that cognition is normative. Cognitive science has much to teach us about how we perceive, remember, reason, inquire, and so on, but unfortunately there is no easy path from these extremely valuable empirical insights to conclusions about how we ought to cognize ... On the other hand, virtue epistemologists agree that the ultimate source of epistemic normativity, and hence the central focus of epistemological inquiry, are cognitive agents and communities, along with the fundamental powers, traits and habits that constitute their intellect. This contrasts with the mainstream approach in later twentiethcentury analytic philosophy, which focuses on individual beliefs and inferences, instead of individuals and their cognitive character (Turri \& Sosa: 1-2, second emphasis added). http://john.turri.org/research/VE_entry_Sage.pdf

I think not much consideration is needed to undermine these three claims. To do this, please return to the Descartes quotation given earlier, reading with special emphasis those elements of it which are normative, deontic, and pertain to agential-level appraisal ("individuals and their cognitive character"). Then consider read some-Locke, Clifford, Chisholm, Alston, and Foley.... All normative epistemology is, well, normative. And the deontic tradition in epistemology is, well, deontic. 'Responsibility' language goes back to the Greeks and is probably innate (Cummins 1996) but it is with the enlightenment that we encounter consistent, principled, universalized deontic value theory - a deontology without special pleading or essentialist constraints on its applicability: a deontology inconsistent with slavery, for example (Lockie 2008). The roots of this modern deontological conception were present in Stoic (and Christian) - as opposed to Aristotelian - virtue theory, whereby "virtue is as possible for the slave as for his master" (Russell 1996: 172 \& cf. Annas 2003, Lockie 2008). This enlightenment, universalized, generalist, unconstrained value theory is the foundation of all our freedoms - intellectual and otherwise - and the attempt to offer an atavistic, restricted, impoverished, particularist simulacrum of its surface form is greatly to be resisted (cf. Lockie 2008). The deontological approach is specifically agential, assessing, normatively, the epistemic agent more stringently than any other normative epistemology (or ethics) - see the quotation from Descartes cited already. The conception of epistemology as normative, deontic and agential cannot be taken as constitutive of virtue-theory, it is central to the living, thriving, deontological tradition (cf. Plantinga 1993) - the Cartesian, enlightenment, universal-enfranchisement, 'ethics of belief' tradition:

To sum up: it is wrong always, everywhere, and for anyone, to believe anything upon insufficient evidence.

If a man, holding a belief which he was taught in childhood or persuaded of afterwards, keeps down and pushes away any doubts which arise about 
it in his mind, purposely avoids the reading of books and the company of men that call into question or discuss it, and regards as impious those questions which cannot easily be asked without disturbing it - the life of that man is one long sin against mankind (Clifford 1999: 77).

What though, of 'phronesis'? In the context of discussions of virtue-pluralism one encounters, both in Aristotle and in current neo-Aristotelian virtue epistemology, claims that phronesis is what unifies the different 'faculties' (virtues) into one thing (a point when applied to virtue-pluralism which would take us beyond the concerns of this paper - but cf. Lockie 2008). As regards our concerns regarding the $U r$ notion of value in virtue epistemology, phronesis is, however, commonly invoked to unify, somehow, responsibility and reliability into one epistemic value.

The problem with this is twofold. One is that 'phronesis' can all too swiftly become (has all too often become) a Magic Ingredient X, a marketing term, or at best a placeholder for the work needing to be done, rather than any explanation of how this work may be done. As regards Aristotelian ethics Simpson (1992: 510) puts matters thus: "This is where Aristotle appeals to the virtue of prudence (phronesis). The mean is what prudence determines to be the mean. This doctrine has struck many readers as singularly unhelpful. What we want is not a discussion of the faculty which does the deciding but of the criterion by reference to which it does so." I agree with Simpson in this judgment - and not simply of Aristotle, and not simply as applied to virtue ethics. The other aspect to this problem is that phronesis, where it is not treated as all things to all people, looks most naturally to be interpreted as an intrinsically deontic, responsibilist 'virtue'.

Ultimately, it is the behavior of persons with phronesis, or practical wisdom, that determines right acting and justified believing, as well as one's moral and intellectual duty and the other evaluative properties of acts and beliefs. For the sake of the unity of the self, it is important that there be forms of these concepts that apply to what a person ought or ought not to do all things considered. The virtue of practical wisdom is, among other things, the virtue that permits a person to mediate between and among all the particular considerations of value in any given situation, and to act in a way that gives each its proper weight (Zagzebski 2000: 175).

This axiology is based on what "a person ought or ought not to do all things considered" where this "considered" presumably means actually, personally, psychologically, cogitatively considered by that person ${ }^{6}$. This involves "evaluative properties of acts and beliefs" under which that epistemic agent is the person whose practical wisdom may "mediate between and among all the particular considerations of value in any given situation." What is this (commendable) axiology but a very deontic, internalist conception of epistemic justification: not some glue to irenically adhere responsibilism with reliabilism, but one half of these two distinct possibilities? As a strong deontic internalist I am committed to defending such a conception of epistemic justification; but it does not serve to elide or efface, to coalesce or finesse, the two-dimensional 
(responsibilist/reliabilist) bifurcation of epistemic value, it just is one (and only one) of those dimensions of epistemic assessment.

In a work of this nature, and in the context of a critical discussion of the role of phronesis, it would be inappropriate not to generalize this discussion to mention a vaguer and more expansive tendency that travels through the last twenty or so years of virtue epistemology, not simply as regards 'practical wisdom', but as regards the enterprise of virtue theory more generally:

Panacea claims - for any given epistemic problem, virtue epistemology (or its attendant concept of 'virtue', or phronesis) offers a uniquely or specially effective resource for solving said problem.

But virtue epistemology is no panacea and must argue closely, with the same analytic precision as any other approach in epistemology (i.e. not merely programmatically or in marketing terms) for any explanatory or normative or descriptive advantages it claims over its competitors.

What then of the view that the virtues themselves unify responsibility and reliability? I have adverted to this view briefly in endnote 3 above. The virtue theorist must ask whether virtue is to be explanans/analysans or explanandum/analysandum. Surely it cannot be both. On the face of it, it should be the first of these alone. We have a task - to explain/account-for/analyze normative epistemology and the things it takes as its objects of study (say, rationality, knowledge, justification - whether of beliefs or agents). This is just as is the case in ethics, where one takes as one's task to explain/account for/analyze normative ethics and the things it takes as its objects of study - as, for instance, in giving an account of the Right or the Good. Virtue theory is a candidate to explain/accountfor/analyze these normative phenomena - as opposed to other candidates (deontic or consequentialist, responsibilist or reliabilist). Virtue theory's ontological or other status is not a given - serving as something to be explained itself - it must earn its keep. For virtue to be sometimes explanans/analysans, yet, when radically called into question, instead a given, an explanandum/analysandum, to be explained or analyzed itself, is, I take it, specifically objectionable.

What then of the 'direction of analysis' point? An objection that is widely canvassed is that virtue theory in ethics or epistemology changes the direction of analysis: we define 'right action' in terms of what the virtuous person would do in these circumstances, and likewise 'rational belief', 'justified belief' and knowledge in terms of what the virtuous cognizer would do or think or believe in.

The core (conjoint) objection to this move is a moral objection allied to an objection from circularity. To claim a metaphysical priority of character/agent over act is morally wrong. It is morally wrong to identify a person or class of persons (for Aristotle, the Athenian nobility ${ }^{7}$ ) and then define 'right act' or 'good outcome' in terms of what they would do or bring about. To make the obvious objection: what if the putatively 'virtuous' agent were to commit a vile act? Here is where the circularity response comes in. This 'direction of 
analysis' move will be buttressed by what in 1998 I identified in the virtue-ethical literature as a 'no true Scotsman' maneuver. A circularity will be invoked to defend the claim that the virtuous agent will, in virtue of the possession of that status, be incapable of believing irrationally, or being epistemically unjustified, or lacking knowledge: the [truly] virtuous cognizer could not, in virtue of that fact, be epistemically deficient in these regards.

This objection would have teeth even were we to restrict ourselvelves to thoughtexperiment cases of obviously unjustified yet stipulated-as-virtuous believers; but there are actual figures, including some or all of the greatest thinkers in human history, who are clearly cognitively virtuous yet clearly lack (here, for these examples) knowledge. Newton, for example, believed in absolute simultaneity yet was wrong in this. Aristotle believed beetles were spontaneously generated from mud. These figures were epistemically virtuous if any were - but they were wrong.

Attempts to save this 'direction of analysis' move against these obvious objections by terminological maneuvers are not well taken (e.g. Zagzebski's 1996 distinction between Newton's acting virtuously and Newton's performing an act of virtue). Such maneuvers, as noted, are merely terminological; and anyway make repair to just the two bifurcated axes of normative-epistemic appraisal which were meant to be combined by virtue theory's 'agent first' direction of analysis move - yet now are needed by the defender of said move in turn. Attempts to concede ground here when it comes to knowledge but save the 'direction of analysis' maneuver when it comes to, for example, epistemic justification, will be merely to concede what has been argued above: that virtue theory precisely does not 'unify' both deontic and consequentialist value properties into a single term. Claiming, for example, that the virtuous cognizer (Aristotle, Newton) might unavoidably lack knowledge, but, in virtue of being 'virtuous' could not be unjustified, indeed accords with ordinary language usage, but marks the concession that virtue theory does not combine the reliabilist with the responsibilist - instead coming down heavily on one side (the deontic side) of this division. This is a point emphasized by the Stoic (as

opposed to the Aristotelian) tradition in virtue theory (cf. Annas 2003) and persisting into the early modern period:

men everywhere give the name of virtue to those actions, which amongst them are judged praiseworthy; and call that vice which they account blamable... (Locke 1975: II,28; cited in Goldman 2001: 30).

\section{Halo effects and the Right versus the Good}

Defining for [neo-Aristotelian] 'mixed' virtue theory of whichever emphasis, responsibilist or reliabilist, is that 'virtue' as a (motivated) term of art, requires we be situated in the top left sector of the epistemic circumplex detailed in Figure One above: that is, that we have objectively achieved the Epistemic Good (actually attained truth/avoided falsity) and we have done so in a diligent, praiseworthy, responsible (etc.) fashion - that we have done so in a way that is Epistemically Right (say, roughly, in a 
fashion that respects the requirements of intentionally seeking after truth/avoiding falsity). Achieving only one of these in the absence of the other isn't simply, well, to achieve one epistemically valuable thing and miss another. It is to be essentially incomplete in epistemic [ethical] achievement per se. Examples here abound, switching freely from the ethical to the epistemic and back. Zagzebski claims (after Nagel) that the Nobel prize is not given to people who are wrong ${ }^{8}$, and then uses the moral example of a compassionate agent giving money to a fraudulent beggar "This is not, of course, to suggest that we would withhold praise of the agent, but her act would not merit the degree of praise due it if the beggar really were deserving" Zagzebski (1999: 107). Brian Weatherson, in defending (as he sees it) the deontic conception of epistemic justification, employs an ethical example precisely akin to that of Zagzebski's 'beggar' case before drawing his intended epistemic conclusion. Despite intending to defend epistemic deontology rather than virtue theory, he draws a conclusion strikingly close to Zagzebski's:

imagine two people dive into ponds in which they believe there are drowning children. The first saves two children. The second was mistaken; there are no children to be rescued in the pond they dive into. Both are praiseworthy for their efforts, but they are not equally praiseworthy. ... praiseworthiness depends on outputs as well as inputs, and if the victim of deception produces beliefs that are defective, i.e. false, then through no fault of their own they are less praiseworthy (Weatherson 2008: 567).

Clifford however, uses his famous example of the ship-owner, permitting a voyage to take place in a ship he believes to be unseaworthy, to argue against the view that the nature of the outcome consequent upon an action should affect our normative appraisal of that action. He contrasts the case where a ship indeed is unseaworthy with one where, unbeknownst to said owner, it is not:

Let us alter the case a little, and suppose that the ship was not unsound after all; that she made her voyage safely, and many others after it. Will that diminish the guilt of her owner? Not one jot. When an action is once done, it is right or wrong for ever; no accidental failure of its good or evil fruits can possibly alter that. The man would not have been innocent, he would only have been not found out. The question of right or wrong has to do with the origin of his belief, not the matter of it; not what it was, but how he got it; not whether it turned out to be true or false, but whether he had a right to believe on such evidence as was before him (Clifford 1999: 71).

I have argued (Lockie 2014a, 2018) that the Weatherson / Zagzebski type of argument derives its dialectical force from what the social psychologists, after Thorndike, call a 'halo effect' - one that is both ubiquitous and pernicious in epistemology. Pace Weatherson, both of his would-be-rescuers are indeed equally praiseworthy - just as both of Clifford's ship-owners are, as Clifford correctly notes, equally blameworthy. Praiseworthiness and blameworthiness - deontology's positive and negative terms - 
pertain wholly and solely to the Right (and see pervasive talk of 'credit'/'discredit' for epistemic conduct in the recent virtue epistemic literature). In each of the cases contrasted by the thought experiments above (drowning, beggar, ship, Nobel-prize) there is of course a huge difference in the Good, a difference dependent upon the outcome's consequentialist yield; but none at all in the Right. This is not merely a terminological point: the putatively deontic terms of praise or blame are profoundly embedded within ethical and epistemic theory. A failure to be very clear in distinguishing the Right from the Good leads to compounded errors in ethics and epistemology. I have argued (Lockie $2014 b$ ) that this type of error derives to a large extent from a flawed framework metaepistemology: the view that deciding such questions must consist in testing such cases as the above against our immediate, ('pre-theoretical') intuitions. Immediate, pre-theoretical intuitions may indeed militate against Clifford and with Weatherson and Zagzebski; but were they to do so, this would be simply in virtue of an unscrutinized intuitive awareness that in such cases as these there is a major difference in some species of ethical or epistemic success or failure. In each such case we need to be explicit on what species of success or failure this is and not permit a 'halo effect' of generalized axiological failure to smear from one axis of epistemic assessment to the other.

\section{References}

Alston, W. (1985) “Concepts of Epistemic Justification,” Monist, 68(1): 57-89 reprinted in his Epistemic Justification, Ithaca: Cornell University Press 1989, 81-115.

Annas, J. (2003) "The Structure of Virtue," in L. Zagzebski \& M. de Paul, (eds) Intellectual Virtue: Perspectives from Ethics and Epistemology, Oxford: Oxford University Press.

BonJour, L. (1985) The Structure of Empirical Knowledge, Cambridge MA: Harvard University Press.

Chisholm, R. (1956a) "Epistemic Statements and the Ethics of Belief," Philosophy and Phenomenological Research XVI, 4.

Chisholm, R. (1956b) “The Concept of Empirical Evidence,” Journal of Philosophy, 53.

Clifford, W. K. (1999) "The Ethics of Belief," in The Ethics of Belief and Other Essays, Amherst, New York: Prometheus Books.

Cummins, D. (1996) "Evidence for the Innateness of Deontic Reasoning," Mind \& Language, 11: 160-190.

Descartes, R. (1931) Philosophical Works of Descartes Vol. 1, eds E. Haldane \& G. Ross, Cambridge: Cambridge University Press.

Feldman, R. (2002) "Epistemological Duties," in The Oxford Handbook of Epistemology, ed. P. Moser, Oxford: Oxford University Press. 
Foley, R. (2004) "A Trial Separation Between the Theory of Knowledge and the Theory of Justified Belief," in John Greco ed. Ernest Sosa and his Critics, Wiley.

Goldman, A. (1986) Epistemology and Cognition, Cambridge, Mass: Harvard University Press.

Goldman, A. (2009) "Internalism, Externalism and the Architecture of Justification," Journal of Philosophy, 106 (6): 1-30.

Greco, J. (2002) "Virtues in Epistemology," in P. Moser (ed.) The Oxford Handbook of Epistemology, Oxford: Oxford University Press.

Locke, J. (1975) Essay Concerning Human Understanding, ed. P.H. Niddich, Oxford: Oxford University Press.

Lockie, R. (2018) Free Will and Epistemology: A Defence of the Transcendental Argument for Freedom; London: Bloomsbury Academic.

Lockie, R. (2016a) "Perspectivism, Deontologism and Epistemic Poverty," Social Epistemology, 30(2), 133-149.

Lockie, R. (2016b) "Response to Elqayam, Nottelmann, Peels and Vahid on My Paper 'Perspectivism, Deontologism and Epistemic Poverty'," Social Epistemology Review and Reply Collective 5(3), 21-47.

Lockie, R. (2014a) "The Regulative and the Theoretical in Epistemology," Abstracta, 8(1), 3-14. ISSN 1807-9792.

Lockie, R. (2014b) "The Epistemology of Neo-Gettier Epistemology," South African Journal of Philosophy, 33(2), 247-258.

Lockie, R. (2008) "Problems for Virtue Theories in Epistemology," Philosophical Studies, 138(2), 169-191.

Plantinga, A. (1993) Warrant: the Current Debate, Oxford: Oxford University Press.

Russell, B. (1996) A History of Western Philosophy, London: Routledge.

Sartwell, C. (1991) "Knowledge is Merely True Belief," American Philosophical Quarterly, 28 (2): 157-65.

Sartwell, C. (1992) "Why Knowledge is Merely True Belief," Journal of Philosophy, 89 (4): $167-80$.

Simpson, P. (1992) "Contemporary Virtue Ethics and Aristotle," Review of Metaphysics 45: 503-24. 
Turri, J. \& Sosa, E. (2013) "Virtue Epistemology," forthcoming in: Encyclopedia of Philosophy and the Social Sciences, edited by: Byron Kaldis, Sage. Downloaded at http://john.turri.org/research/VE_entry_Sage.pdf

Weatherson, B. (2008) “Deontology and Descartes' Demon," Journal of Philosophy, 105: 540-569.

Weinberg, J. M. (2006) "What's Epistemology For? The Case for Neopragmatism in Normative Metaepistemology," in Epistemology Futures, Stephen Hetherington (ed.) OUP: $26-47$.

Wright, S. (2013) "A neo-Stoic Approach to Epistemic Agency," Philosophical Issues, 23: 262-275, Epistemic Agency edited by Ernest Sosa \& Enrique Villanueva, guest editor Baron Reed.

Zagzebski, L. (1999) "What is Knowledge?" in J. Greco \& E. Sosa, (eds) The Blackwell Guide to Epistemology, Oxford: Blackwell.

Zagzebski, L. (2000) "Précis of Virtues of the Mind," Philosophy and Phenomenological Research, 60 (1).

\section{Further Reading}

Lockie, R. (2008) "Problems for Virtue Theories in Epistemology," Philosophical Studies, 138(2), 169-191. (Tracks some of the points made in this paper; but is augmented by many others into, overall, a rather stringent critique of virtue epistemology as a whole).

Lockie, R. (2018) Free Will and Epistemology: A Defence of the Transcendental Argument for Freedom; London: Bloomsbury Academic.

\section{BIOGRAPHICAL NOTE}

Robert Lockie has an academic background in psychology as well as philosophy. He works on free will and responsibility (epistemic and ethical), normative epistemology (justification, rationality and knowledge), metaphilosophy, and issues in the philosophy of mind and psychology. He is Senior Lecturer in the Psychology Department, University of West London, Paragon House, Brentford TW8 9GA U.K. bob.lockie@uwl.ac.uk 


\section{Notes}

1 The 'ethics of belief' tradition from Descartes embraces two things: epistemic deontology ('responsibilism') and internalist access restrictions. As Plantinga (1993) notes in his masterful review, these may come apart; as when one is a deontologist without access restrictions or embraces access restrictions without deontology. Although these are both positions in logical space, and with actual adherents, they possess profound problems of both internal philosophical motivation and logical coherence, for which read Plantinga (1993) and Lockie (2018). What Plantinga (1993) calls 'classical deontological internalism' and Alston (1985) calls ' $\mathrm{J}_{\mathrm{di}}$ ' - deontic, internalist, justification - involves the conjunction of deontologism with internalism: whereby the deontology leads to the internalist access restrictions via 'ought' implies 'can'. I contend (Lockie, 2018) that deontology and internalism should not be teased apart; and in this contribution I am embracing, after Descartes, Clifford, Plantinga et al, 'classical deontological internalism', whereby internalism and deontology do not come apart. 'Ought' implies 'can' is, I contend, a priori; and if you embrace epistemic 'oughts' (deontology) you must acknowledge epistemic 'cans' (internalist access restrictions).

${ }^{2}$ Deontic approaches are sometimes identified with rules-based approaches. Although not entirely a straw man, doing this is nevertheless a mistake. Some externalisms / consequentialisms are themselves rules-based (Goldman's 'J rules' / rules-utilitarianism). And some deontological / internalist positions aren't rule based. What matters is the source of the normativity, not its surface form. Any value theory based in a sui generis notion of obligation (plus all concomitant - e.g. 'ought' implies 'can' accompaniments) is a deontic theory.

${ }^{3}$ One might think that 'virtue' ought to be seen only as explanans/analysans rather than explanandum/analysandum; but this is not always so. At this stage I leave for the reader to decide whether this may constitute a critical point against 'virtue', so-conceived - we return to this point below.

${ }^{4}$ These italics (added) answer to my later desiderata in this paper and should not distract the reader now.

${ }^{5}$ Above, I distinguish mixed virtue theory from pluralism, taking an in depth discussion of the latter to be beyond the concerns of this paper. It should be noted that certain pluralists appear to claim there is no unifier: that virtue epistemology employs reliabilist virtues and responsibilist virtues (and, presumably, a mixture of both). I leave the reader to decide whether he or she feels this to be a satisfactory stance. One might wish to ask of any such stance, in virtue of what such a heterogeneity of items are all 'virtues'. One might also wish to note that virtue theorists from Aristotle onwards are chronically inexplicit about their relationship to pluralism. For Aristotle, notions such as 'phronesis' and 'justice' seem to broaden or narrow in scope quite wildly, as the demands of argument would have it: sometimes appearing to explicitly replace his pluralism with a uninomic account, and sometimes quite definitely not. But, as noted, I take an in depth discussion of pluralism to be beyond the scope of this paper - see Lockie (2008) for more of my views. 
${ }^{6}$ Actually, for a number of epistemologists (take Alston as a paradigm, across a series of very fine papers) this point is - tacitly or explicitly - equivocated upon. If "all things considered" means actually considered by that person this becomes a statement of deontic internalism. If "all things considered" means from the God's eye view this becomes a strong externalism. Cf. Lockie (2018, 2014a, 2016b)

7 This, (in my 2008), I suggested reveals the patrician, pre-enlightenment origins of Aristotle's virtue theory. He was writing for the elite, the polis (not even the demos, already restricted to the free men of Athens, but specifically the nobility - cf. Simpson 1992). There is an intrinsically anti-enlightenment slant to any theory which identifies a privileged 'virtuous' elite and defines 'virtuous act' in terms of said elite. What the person does must come first and we judge them normatively after that.

${ }^{8}$ I have argued she is wrong in the moral she draws here (Lockie 2008). Most of the greatest thinkers known to intellectual history are known to us to have been wrong - we revere them for their intellectual 'virtue' nonetheless. See Annas (2003) for this point as applied to Socrates. 